\title{
テオフィリン徐放性製剤での唾液中濃度と血中濃度との相関関係*1
}

\author{
松尾直枝, 梅村みどり, 近藤由利子*2, 松井純一*3, 足高 毅, 福島保喜*4 \\ 東邦大学医学部附属大䔉病院薬剤部 $* 2$, 同病院小览科*3, 同病院第二内科*4
}

\section{Correlation between Plasma and Saliva Concentrations of Theophylline by Sustained-Release Theophylline Preparation (Theo-Dur $\left.{ }^{\circledR}\right)^{* 1}$}

\author{
NAOE MATSUO, Midori UMEMURA, YURIKo KONDO*2, JUN-ICHI MATSUI*3, \\ TSUYOSHI ASHITAKA, YASUNOBU FUKUSHIMA*4 \\ Hospital Pharmacy*2, Department of Pediatrics*3, The 2nd Department of Internal \\ Medicine*4, Toho University School of Medicine and Ohmori Hospital
}

(Received January 5, 1987)

\begin{abstract}
In order to investigate the predictability of theophylline concentrations in plasma from those in saliva, the total concentration (bound plus free) in plasma $(\mathrm{Pt}$ ) and the free (unbound) concentration (Pf) were compared with the concentration in saliva ( $\mathrm{S}$ ), respectively.

Ten healthy males and three females were orally administrated a sustained-release theophylline preparation (Theo-Dur ${ }^{\circledR}$ ) by a single dose of $8.13 \mathrm{mg} / \mathrm{kg}$ and then, as the second experiment, six out of the above thirteen volunteers were administrated $400 \mathrm{mg}$ of theophylline daily for five days.

In the experiment of the single dose, there was no significant difference in the elimination half-life of theophylline between plasma and saliva. And both the ratios of S/Pt and S/Pf were $0.61,1.60$, respectively, up to 24 hours of dosing. In the case of multiple dose administration, 33. 3 and $61.1 \%$ of the predicted $\mathrm{Pt}$ and $\mathrm{Pf}$ values which were calculated from the $\mathrm{S} / \mathrm{Pt}$ and $\mathrm{S} / \mathrm{Pf}$ for each volunteer coincided with the measured values within the deviation of $\pm 10 \%$, respectively. Moreover, S/Pt and S/Pf in the second experiment made a great change in comparison with them in the experiment of the single dose. From these results it was concluded that the use of saliva to predict theophylline concentrations in plasma has an substantial error and may lead to incorrect dosage adjustments.
\end{abstract}

Keywords_-sustained-release theophylline preparation; saliva concentration; correlation between plasma and saliva concentrations; prediction of plasma concentration

\begin{abstract}
緒
近年，わが国においても各医療施設で，薬物血中濃度 の測定とその解析による投与管理が推進されている。ま た，頻回にわたる採血の負担を軽減し，時間・場所にも 制約されない万法として, 唾液中の薬物濃度の測定が試 みられており1，気管支喘息治療薬として広く用いられ ているテオフィリンについても, その血液中扰よび重液

*1 日本薬学会第 105 年会（金沢，1985年 4 月）で挠 表.

*2 4 東京都大田区大森 6 丁目 11-1；11-1, Ohmori 6-chome, Ohta-ku, Tokyo, 143 Japan
\end{abstract}

中濃度の相関関係に関する報告が多く見られるようにな った2 5).

一方, テオフィリンの血中濃度変化を最小限に抑え, 一定の血中濃度をより長時間保つような, 種々の徐放性 製剂が開発され，TDM (Therapeutic Drug Monitoring) を実施する上で，これら製剤服用時の体内動態を把握し ておくことも必要になってきた。

そこで, 今回著者らは, 東邦大学大森病院で繁用され ているテオフィリン徐放性製剂を用いて，その体内動態 を確認するととるに，唾液中濃度を同時に測定し，血中 濃度との相関関係を調べた．また，テオフィリン連続投 与時に拈ける血中濃度の唾液中濃度測定による予測の可 
能性についても検討した。ささらに, 唾液中濃度は, 血中 非結合型薬物濃度にほぼ等しいとも考えられている ので, 非結合型濃度に関しても同様の検討をしたので, その結果も合わせて報告する。

\section{試 験 の 部}

試験には, 本試験の意図を理解した上で, 13名（男 10, 女 3 ）の健康成人が参加した（Table 1).

内服試験は, 以下の方法で実施した.

\section{試験 I : 単回投与試験}

テオフィリン徐放錠 (Theo-Dur ${ }^{\circledR} 100 \mathrm{mg}$ 錠, 日研化 学, Lot No. B65; 以下 TP 錠) を, 体重当り 8〜10mg を目安として 約 $150 \mathrm{ml}$ の水と共に投与した. ただし, その量が $500 \mathrm{mg}$ をこえる場合は $500 \mathrm{mg}$ の投与とした.

被験者には, TP 錠投与の少なくとも24時間前から試 験終了まで, 紅茶などのキサンチン類含有物の摂取を禁 止した。また，絶食条件は，TP 錠投与の12時間前から 5 時間後までとし，この間の水以外の飲食を禁止した.

血液は,投与前执よび投与後 $0.25,0.5,1,2,4,7$, 12, 24時間に, 肘静脈から 1 回約 $3 \mathrm{ml}$ をDry EDTA 加 採血管採取した. 採血後は速やかに血漿を分離し, さら にその約 $1 \mathrm{ml}$ はアミコン侏製の限界ろ過用容器 (MPS1) 飞移し, $25^{\circ} \mathrm{C}, 1,000 \mathrm{rpm}$ (KOKUSAN, H-103RS) で10分間遠心した。 また, 採血と同時に, 口中に綿花を 含んで刺激する方法で混合垂液(以下液)を採取した. 採取した血獎および垂液は，定量時までそれぞれ冷凍お
よび冷蔵保存した。

\section{試験 II：連続投与試験}

試験 I 終了後, 2 週間以上時間をおいたのち，13名の被 験者のうち任意の 6 名に TP 錠 1 日 $400 \mathrm{mg}$ ( 8 時, 20 時), 5 日間の連続投与試験を実施した。血液および唾液 の採取は, 報告開始 3 日目， 4 日目，5 日目の15時に試 験 I と同様の方法で行った。なお，大森・猪爪ら ${ }^{8,9)}$ に より，食事の影響がないことが報告されているので, こ の試験の期間中は, 特に食事の制限をしなかった。

\section{測定法}

血中総テォフィリン濃度 (以下 $\mathrm{Pt}$ ), 同非結合型濃度 （以下 Pf）および垂液中テオフィリン濃度（以下 $\mathrm{S}$ ) は，いずれもEMIT®法を用いて測定した。なお，著者 らは，EMIT 法で唾液中の薬物濃度測定が可能である こと，および，口中に綿花を含んで垂液を採取する方法 は，薬物濃度測定に支障をきたさないことを確認してい る.また, 倳液の冷蔵保存についても採取後 2 週間ま で, 測定結果に変動のないことを確認している.なお, 今回の試験では, 事前に日内の唾液 $\mathrm{pH}$ 変化を調べた結 果と Mucklow ら ${ }^{7)}$ の報告より, 重液の $\mathrm{pH}$ について 特に考虑しなかった。

\section{結果}

\section{1. 単回投与試験}

(1) 血液および垂液中濃度 : 被験者に TP 錠を 1 回投 与. $(8.13 \pm 0.75 \mathrm{mg} / \mathrm{kg}$; mean \pm S.D. $)$ した後の $\mathrm{Pt}$,

Table 1. Subjects Characters

\begin{tabular}{cccccc}
\hline $\begin{array}{c}\text { Subj. } \\
\text { No. }\end{array}$ & Sex & $\begin{array}{c}\text { Age } \\
(\text { yr. })\end{array}$ & $\begin{array}{c}\text { Height } \\
(\mathrm{cm})\end{array}$ & $\begin{array}{c}\text { Weight } \\
(\mathrm{Kg})\end{array}$ & $\begin{array}{c}\text { Smoking } \\
\text { habit }\end{array}$ \\
\hline 1 & M & 26 & 174 & 67 & 0 \\
2 & M & 25 & 165 & 52 & 0 \\
3 & M & 29 & 169 & 68 & - \\
4 & M & 30 & 170 & 60 & 0 \\
5 & M & 27 & 172 & 62 & 0 \\
6 & M & 27 & 179 & 72 & 0 \\
7 & M & 24 & 163 & 58 & 0 \\
8 & M & 29 & 170 & 60 & 0 \\
9 & M & 25 & 167 & 67 & - \\
10 & F & 27 & 154 & 45 & - \\
11 & F & 24 & 156 & 65 & - \\
12 & M & 24 & 168 & 61 & - \\
13 & F & 26 & 152 & 46 & - \\
\hline
\end{tabular}




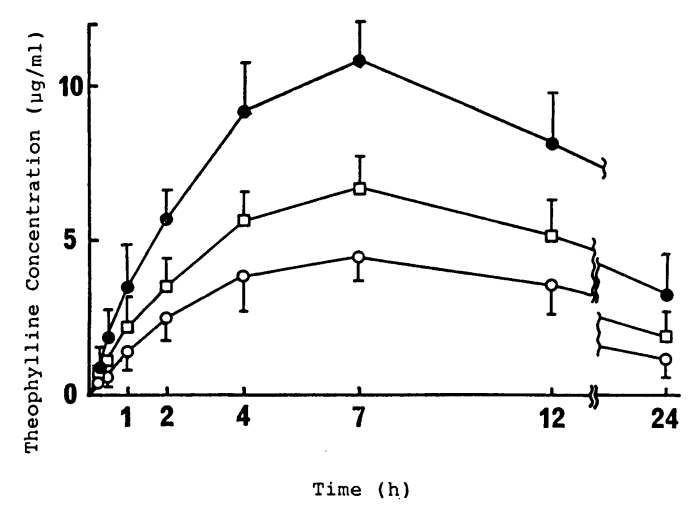

Fig. 1. Time Course of Plasma and Saliva Theophylline Concentration after Administration of Sustained Release Theophylline to 13 Healthy Volunteers (mean \pm S.D.)

- - Plasma total; - $\bigcirc-$ Plasma free;
$-\square$ - Saliva

Pf, S の変化を Fig. 1 に示した. 各濃度とも, 投与後 約 6.8 時間でピークに達し以後次第に減少した. 消失相 の生物学的半減期 (mean 土 S.D.) はそれぞれ, 7.08土 $1.18,6.01 \pm 1.86,6.15 \pm 1.35$ 時間で, 各值の間には有 為な差は認めず $(P>0.01)$, 契煙習慣の有無による差も 認められなかった $(\mathrm{P}>0.001)$. な拈, 生物学的半減期 は, 消失相の実測值から最小二乗法により求めた。

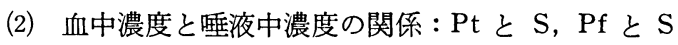
の関係をそれぞれ，Fig. 2A，Fig. 2B に示した。いず れもほぼ 0 を通る直線となり，その相関係数はそれぞれ 0.987，0.955であった.

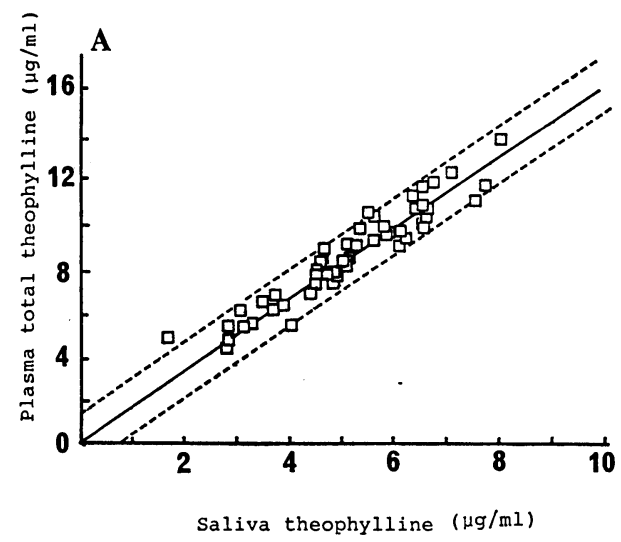

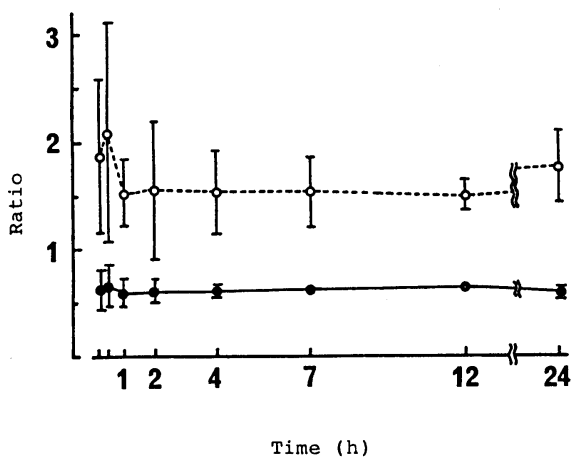

Fig. 3. Ratios of S/Pt and S/Pf of Theophylline Concentrations in 13 Volunteers after Single Oral Dose Administration (mean \pm S.D.)

$-\mathrm{S} / \mathrm{Pt} ;-\mathrm{O}-\mathrm{S} / \mathrm{Pf}$

$\mathrm{S} / \mathrm{Pt}, \mathrm{S} / \mathrm{Pf}$ の服用時間後の变化を Fig. 3 に示した.

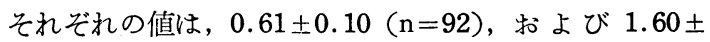
$0.44(\mathrm{n}=91)$ であった.

2. 連続投与試験（ $\mathbf{S}$ からの Pt または Pfへの予測 性）

（1）生体内動態値による予測：単回投与試験で得られ たテオフィリンの体内動態值を用いて，5 日間連続服用 時の Pt および Pf の预測曲線およびそれぞれの実測值 の一例を Fig. 4A, Fig. 4B に示した.

シミュレーション值からさ10\%に存在する実測値の割 合は, 被験者 6 名のそれぞれ 3 個ずつのデータ, 計 18 個 のらち, Pt では $38.9 \%$, Pf では $33.3 \%$ であった.ま た， 3 点すべてが土 $10 \%$ に存在する者はおらず，実測值

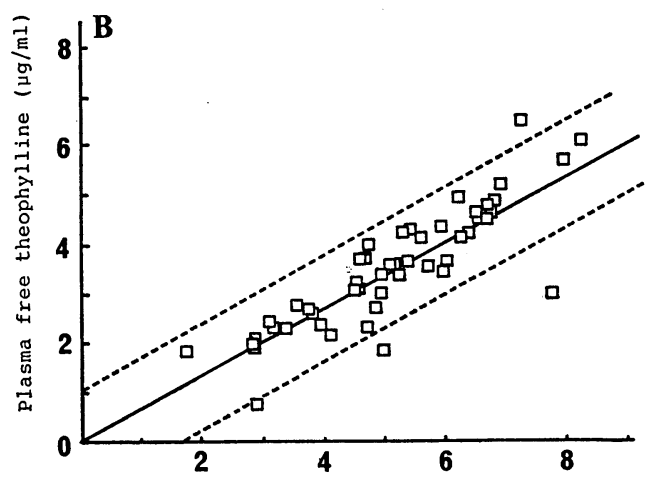

Saliva theophylline $(\mu \mathrm{g} / \mathrm{ml})$

Fig. 2. Carrelation between Saliva and Plasma Theophylline Concentrations in 13 Volunteers after Single Oral Dose Administration

A. Saliva-Plasma total, B. Saliva-Plasma free (95\% confidence interval) 

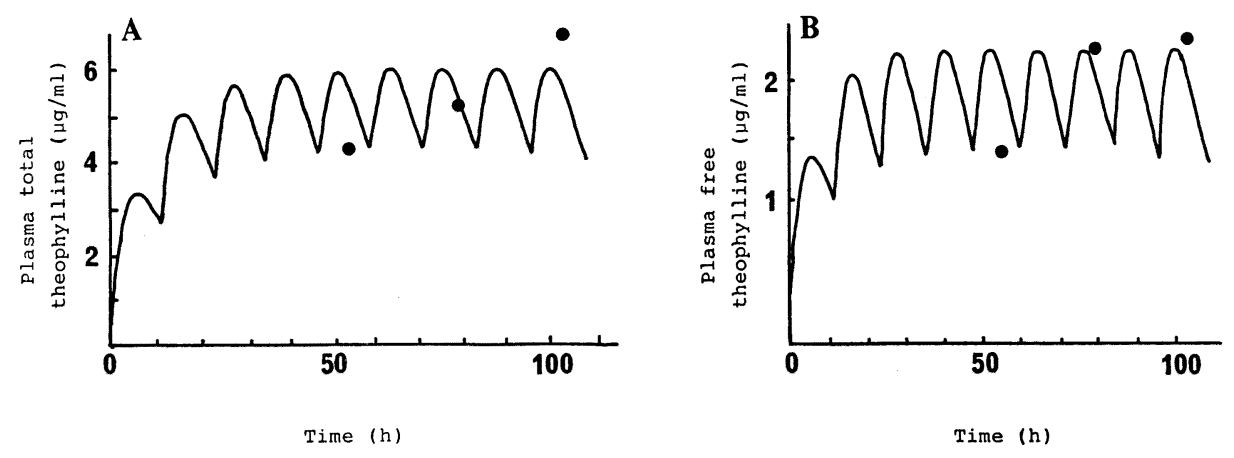

Fig. 4. Expected Plasma Theophylline Concentration during Multiple Oral Dose Administration of Volunteer No.1 (O ; measured mean concentrations)

A. Saliva-Plasma total, B. Saliva-Plasma free
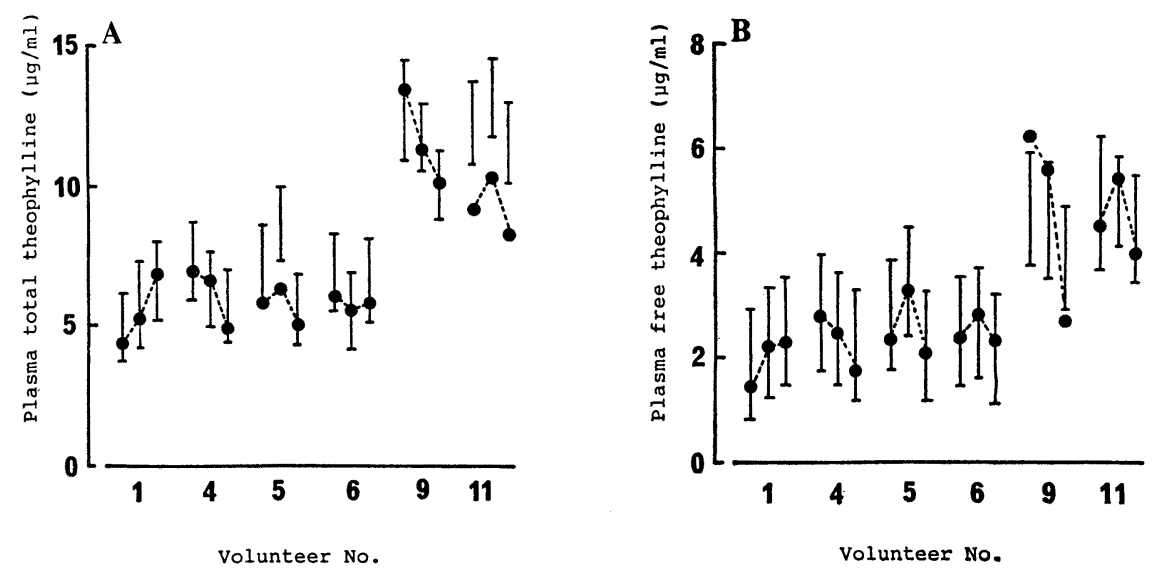

Fig. 5. Theophylline Concentration Predicted from the Regression Line ( ; mean concentrations measured in the $3 \mathrm{rd}, 4$ th and 5 th day from the left) The bard are range of calculated concentration.

A. Saliva-Plasma total, B. Saliva-Plasma free

と予測值の誤差率は $2 \%$ \% $80 \%$ にまでおよんだ。

(2) S-Pt，S-Pf 直線による予測 : Fig. 2 で示した直 線から予測する Pt, Pf 幅と, それぞれの実測值を Fig. 5A, Fig. 5B に示した. Pt では77.8\%, Pf では88.9\% の実測值が予測值の幅の中に存在した。しかし，Pt で は予測值の幅は平均で $2.72 \mu \mathrm{g} / \mathrm{ml}$ で, この值は治療有 効濃度幅が $10 \sim 20 \mu \mathrm{g} / \mathrm{ml}^{10 ~ 14)}$ であることを考学ると， その約 $30 \%$ になる。

(3) S/Pt， S/Pf による予測：各被験者の単回投与試 験時に得られた $\mathrm{S} / \mathrm{Pt}, \mathrm{S} / \mathrm{Pf}$ から予測する Pt, Pf はと れぞれ $33.3 \%, 61.1 \%$ 実測值が予測値幅の中に存在し た.また, Pt の予測值偪は平均 $1.32 \mu \mathrm{g} / \mathrm{ml}$ であった. さらに, 各被験者の単回, 連続両試験の S/Pt, S/Pf を 比較すると，その值の変動率はそれぞれ $3.2 \sim 44.6 \%$,
0〜40.5\% であった.

なお，両試験を通じて錠服用によると思われる体の異 常を訴えた者はいなかった。

\section{考察}

徐放性製剤を用いて治療を進めている患者に TDMを 実施するために, 徐放性製剂服用時におけるテオフィリ ン体内動態を確認し, さらに, 患者の採血に伴う負担の 軽減および夜間あるいは早朝発作時における血中濃度子 測に対する唾液中濃度測定の有用性を検討した。

徐放性製剤での単回投与時における $\mathrm{Pt}, \mathrm{Pf}$ と $\mathrm{S}$ と の相関関係についてのこれまでの報告結果をまとめる と, $\mathrm{S} / \mathrm{Pt}=0.42 \sim 0.89^{4,5,8,16)}, \mathrm{S} / \mathrm{Pf}=1.96 \sim 2.56^{16)}$ で ある. 今回の試験ではそれぞれ0.61，1.60であり, 報告 
されている結果とほぼ等しいか, やや低めであった.と ころで，これら報告されている值に対する評価はさまざ まで, 簡単にまとめると(1)S の利用は Pt の予測に有用 である2,15), (2) S から Ptを予測することは可能と思わ れるが Pf を予測することは困難である゙5,17), (3) S/Pt は，個人差，時間差が大きく， S のは困難である ${ }^{3,4,18 \sim 20)}$ となる.

今回の結果は, 単回投与試験で得られたすべての值を まとめると，Pt，Pf はとれぞれ S と良い相関関係を持 つといえる (Fig. 2) が, たとえば, あらかじめ単回投 与試験等を実施してその患者の体内動態值, $\mathrm{s} / \mathrm{Pt}, \mathrm{S} / \mathrm{Pf}$ を求めて拈いても, あるいは数名のデータから $\mathrm{S}$ と $\mathrm{Pt}$ またはPf の関係式を求めておいても, 後日の S から Pt, Pf を予測することには無理があることを示してい る.

Sからの予測が困難であることに関しては，俥液の流 速, $\mathrm{pH}$, 重液沈渣と薬物の結合 ${ }^{17}$ 口腔粘膜からの逆払 散 などが考兄られているが，さらに徐放性製剂では， 徐放性であるという製剤学上の特長のために, 吸収・分 布の見かけの速度が変動し, S PtまたはPf がパラレ ルに变化する時間帯が限られてしまらのかもしれない，

以上より, 徐放性製剤服用時の血液中テォフィリン濃 度を軼液中濃度を測定することによって予測することは 困難であり，さらに，これを投与設計・投与管理に応用 することは大きな誤りを招く恐れのあることが示唆され た.

\section{引用文 献}

1）斎藤侑也：ファルマシァ，12，387 (1976).

2) G. Levy, E.F. Ellis and R. Koysooko: Pediatrics, 53, 873 (1976).

3) D.L. Uden, K.W. Miller, L.M. Strand, P.B. Johnson and D.E. Zaske: Ther. Drug Monit., 3, 143 (1981).

4) J. Culig, A. Johnson and P. Turner: Br. J.
Clin. Pharmac., 13, 243 (1982).

5）唯野貢司，佃俊男，国分邦男，青木勇，丹羽弘司 : 薬郕学, 43, 128 (1983).

6）田村善蔵, 堀岡正義編 : “薬物血中濃度測定の実 際”, 薬業時報社, 東京, 1981, pp. 99-114.

7) J.C. Mucklow, M.R. Bending, G.C. Kahn and C.T. Dollery: Clin. Pharmacol. Ther., 24, 563. (1978).

8）大森直子，首藤貴代，猪爪信夫，岩奥椧子，飛野 幸子, 中野眞汎: 臨床薬理, 15, 35 (1984)。

9）猪爪信夫, 大森直子, 岩奥玲子, 首藤貴代, 飛野 幸子, 松下涼子, 従二和彦, 中野畺沉, 松倉誠, 東明正, 松田一郎, 本田涼子：臨床薬理, 15,37 (1984).

10) M.M. Weinberger and E.A. Bronsky: J. Pediatr., 84, 421 (1974).

11) K.M. Piafsky and R.I. Ogilvie: N. Engl. J. Med., 292, 1218 (1975).

12) R.I. Ogilvie: Clin. Pharmacokin., 3, 267 (1978).

13) L. Hendeles, M. Weinberger and G. Johnson: Clin. Pharmacokin., 3, 294 (1978).

14) M.M. Weinberger and E.A. Bronsky: J. Dis. Child. 132, 876 (1978).

15) J.H.G. Johkman, G.K. Koeter, R. Schoenmaker, K. de Vries, J.E. Greving and R.A. de Zeeuw: Eur. J. Clin. Pharmacol., 20, 73 (1981).

16）唯野貢司, 中島史恵, 国分邦男, 青木勇, 丹羽弘 司：薬剤学, 43, 137 (1984).

17）上能伊公雄, 長谷川高明, 小倉庸蔵, 横地義郎, 長谷川雅哉, 北沢式文, 高木健三, 佐竹辰夫：臨 床薬理, 15, 39 (1984).

18) E.P. Munch, Ib S $\phi$ ndergaard and B. Week: Allergy, 36, 89 (1981).

19) N.N. Khanna, S.M. Somani, A. Boyer, J. Mi1ler, C. Chua and J.A. Menke: Dev. Pharmacol. Ther., 4, 18 (1982).

20) A.H. Jackson, C. Edward, A.S. Cope, R.A. Stockley and R. Purkiss: Br. J. Clin. Pharmacol., 15, 407 (1983). 